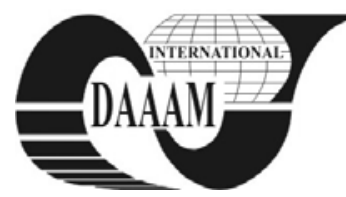

Annals of DAAAM for 2011 \& Proceedings of the 22nd International DAAAM Symposium, Volume 22, No. 1, ISSN $1726-9679$ ISBN 978-3-901509-83-4, Editor B. Katalinic, Published by DAAAM International, Vienna, Austria, EU, 2011 Make Harmony between Technology and Nature, and Your Mind will Fly Free as a Bird Annals \& Proceedings of DAAAM International 2011

\title{
UV HARDENING AND INTERNAL STRESSES IN WATER BASED LACQUERS
}

\author{
AZEMOVIC, E[sed]; HORMAN, I[zet]; VUKAS, N[ikola] \& HAJDAREVIC, S[eid]
}

\begin{abstract}
The work includes precise results of the study of internal stresses in films of water based lacquer, formed on a solid background. Internal stresses arise as the results of changes in volume during hardening and adhesion of the film and substrate. The process of hardening of the investigated water based varnish is achieved by UV radiation. Cantilever method was used to determine the internal strain. The influence of film thickness and the kinetics of internal stresses are examined. There are several periods that can be noticed: the period of intensive evaporation of volatile components and the first appearance of internal stress, the period of increase of internal stress until reaching maximum, the period of retention of maximum stress on the achieved level.
\end{abstract}

Key words: UV hardening, the internal stress, water based lacquer, the cantilever method, film thickness

\section{INTRODUCTION}

All filmogeneous covering that are applied to wood or other surface have the task of protecting the surface from a variety of mechanical damages and of mitigating the impact of external parameters on the surface (temperature, humidity of the air, etc.) or to increase aesthetic properties of the surface or product. The process of film forming begins by applying the water based or some other covering material. In this process, with UV water based lacquers, water evaporation and fusion of the molecules occur, caused by accelerated process of drying using UV rays. These vapors and the chemical reaction of fusion of the molecules cause the shrinkage of the film that is at the same time connected to the surface by adhesive forces. The result of these changes is the internal stress in the film. The internal stresses in the film can cause separation of lacquer from the surface and cracking of the lacquer (Axelsen, 2008).

\section{THEORY OF INTERNAL STRESSES}

When observed in physical way, the cause of the formation of internal stresses is unevenness in changes in board size of the system of film-surfaces, if the film and the surface are simply imagined as plates. All water materials used in surface protection of wood are subject to volume change (shrinkage) during the period of hardening on the surface. In the film material applied to a rigid substrate, shrinkage is possible only perpendicular to the surface, while dimensional changes of the film in the plane of surface prevents the adhesion of the film and substrate (Volinsky et al., 2002).

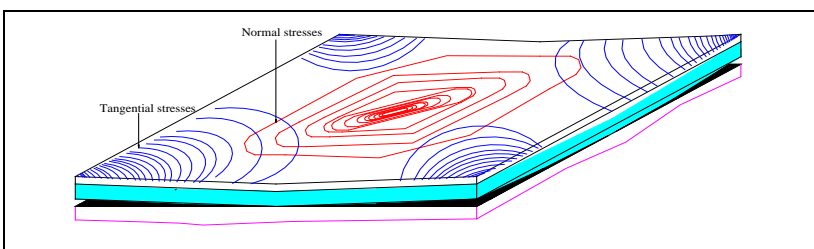

Fig. 1. Positions of stresses of hardened varnish applied to rigid surface
Volume change of the film leads to internal stresses in the film, which is strung on stretch, while on the border filmsurface appears shear stress, Figure 1. Internal stresses are specifically expressed in dimensionally unstable surfaces such as wood and wood products (Vukas et al., 2010).

The total internal stress in films of surface treatment of wood was determined by expression (1):

$$
\sigma=\frac{E_{1} S^{3}}{6 R t(S+t)\left(1-\mu_{1}\right)}+\frac{E_{2}(S+t)}{2 R\left(1-\mu_{2}\right)}
$$

where: $\mathrm{S}$ - thickness of the plate [mm], $\mathrm{t}$ - film thickness [mm], $E_{1}$ - Modulus of elasticity of the surface [MPa], $E_{2}$ - Modulus of elasticity of the film [MPa], $\mu_{1}$ - Poisson's coefficient for the surface, $\mu_{2}$ - Poisson's coefficient for the film, $\mathrm{R}$ - radius of curvature $[\mathrm{mm}]$.

During the hardening of the film of polymer materials, internal stresses are followed by the famous sequence of changes characteristic for all macromolecular systems, and there are three different periods in their development. In period $\mathrm{I}$, the film is in liquid form, there are intensive loss of volatile components and the first appearance of internal stresses in the film. In period II, internal stresses are noticeable and their intensive growth to a maximum value. In the final period III, maintenance of maximum stress in the film is visible.

\section{MATERIALS AND METHODS}

In recent years, there have been great changes in production and use of products for surface treatment of wood. Greater attention is paid to systems that pollute the environment less and require less energy. For the experimental analysis of internal stresses UV water-based varnish was used. Watersoluble varnishes, also known as water- based varnishes are solvents or dispersions of adhesives (resin) in water with the presence of certain amount of organic solvents. The basic properties of UV water based materials are given in Table 1.

\begin{tabular}{|c|c|}
\hline Property & \\
\hline Basic & Acrylic resin \\
\hline Specific gravity [g/cm ${ }^{3}$ ] & 1,04 \\
\hline Dry substance content [\%] & 32,3 \\
\hline Viscosity [mPa.s] & 750 \\
\hline
\end{tabular}

Tab. 1. The main properties of the water based UV lacquer used in tests

Application of UV water based lacquer on the surface is electronic, by the method of airless dispersion. It is the dispersion of materials using substantial static pressure that causes rapid release of the liquid material into the atmosphere. The air is opposed to the movement of fluid in the atmosphere. Dispersion is present when opposing forces overcome the forces of cohesion of the liquid (Grigore et at., 2005). 
Process of drying (hardening) begins by applying the water based lacquer on the surface. The entire drying process is carried out in a sealed UV chamber. The combined drying process of convection and radiation is carried in the chamber.

The first two phases of drying are the convection with temperature (phase I $27^{\circ} \mathrm{C}$, phase II $54^{\circ} \mathrm{C}$ ). Drying time of the film in phase I was $3.5 \mathrm{~min}$ and in phase II was $3 \mathrm{~min}$. The other two phases of drying are radiation, or hardening process with ultraviolet rays. The source of these rays in phase III are lowpressure mercury lamps $60 \mathrm{~W}$ and operating temperature was 40 ${ }^{\circ} \mathrm{C}$, in phase IV sources are high-pressure mercury lamps $1000 \mathrm{~W}$, operating temperature $700{ }^{\circ} \mathrm{C}$. The duration of drying of the film in phase III was $5 \mathrm{~min}$ and in stage IV was $1.5 \mathrm{~min}$. The total process of drying of the film by this method is $13 \mathrm{~min}$.

For the experimental analysis of internal stresses cantilever method was used. The essence of the method is that on one side of a thin, narrow and long panel made of elastic material, which characteristics are known, a film of material is formed. During the hardening of the film, due to the appearance of shrinkage and adhesion forces, the new biplate is being bent. As its length is much greater than the width, the board is bent into a cylindrical surface (Vela et al., 2003). By measuring the radius of curvature (R), deflection of the plate (f) or of deflection of the console panel (h), which is wedged at one end, as shown in Figure 2, internal stresses in the film of the applied materials can be determined.

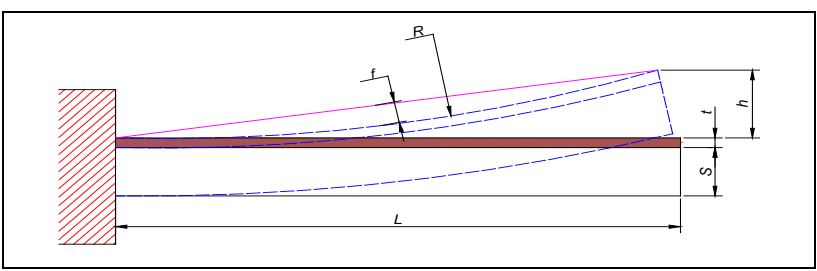

Fig. 2. Chart of the cantilever method

On the Figure 2 are: $\mathrm{S}$ - surface thickness, $\mathrm{t}$ - film thickness, $L$ - length of the surface with the film, $R$ - radius of curvature, $f$ - deflection, $\mathrm{h}$ - deflection of the console.

Between R, $\mathrm{f}$ and $\mathrm{h}$ there is a dependence given by the expression:

$$
R=\frac{L^{2}}{8 f}=\frac{L^{2}}{2 h}
$$

where: $\mathrm{L}$ - length of the plate; $\mathrm{h}$-deflection of the console. On the basis of relation (1) and displayed expression (2) internal stresses in the film of polymer material can be determined through next equation (3):

$$
\sigma=\frac{h E_{1} S^{3}}{3 L^{2} t(S+t)\left(1-\mu_{1}\right)}+\frac{h E_{2}(S+t)}{L^{2}\left(1-\mu_{2}\right)}
$$

With cantilever method of testing of polymer materials' films for surface treatment of wood, expression (3) without the second member is used, because E1>>E2 and $\mathrm{d}>>\mathrm{t}$. The second member of the expression is less than $1 \%$ and can be ignored. Metal is most commonly used as a basis for testing through this method. For this test of the internal stresses in the film, the metal used is aluminum, with basic characteristics: Modulus of elasticity: $7 \times 10^{4}[\mathrm{MPa}$ ], Poisson's coefficient: 0,346 and surface dimensions: $100 \times 13 \times 0,18$ [mm].

\section{RESULTS AND DISCUSSION}

The results of internal stresses in UV water based lacquer were obtained in this experimental analysis. This UV water based lacquer was applied twice electronically on the surface, by the method of vacuum dispersion and dry films of different thickness were obtained, Figure 3.

In this study the total process of drying of the lacquer on the surface lasted $0.5[\mathrm{~h}]$. During this drying process, at various time intervals $0 ; 0.13 ; 0.3 ; 0.5$, [h], displacement of the console was measured.

The obtained values of internal stresses are different, Figure 3. The maximum stresses are $\sigma=0,65 \mathrm{MPa}$ for UV water based film that has a dry film thickness $\mathrm{t}=50 \mu \mathrm{m}$, and for a dry film thickness $t=30[\mu \mathrm{m}]$, the maximum stresses are $\sigma=2,02 \mathrm{MPa}]$. It can be seen that film with small thickness has higher stress in the film and that the curves of the stresses follow the kinetics of internal stresses. In period I, there is intense evaporation of the volatile components, or the appearance of internal stresses. In period II, we have the maximum internal stresses $\sigma_{\max }=2,02$ $\mathrm{MPa}$, in 30 (min). In period III, we have the retention of maximum stress and its constant maintenance as the limit of the stress.

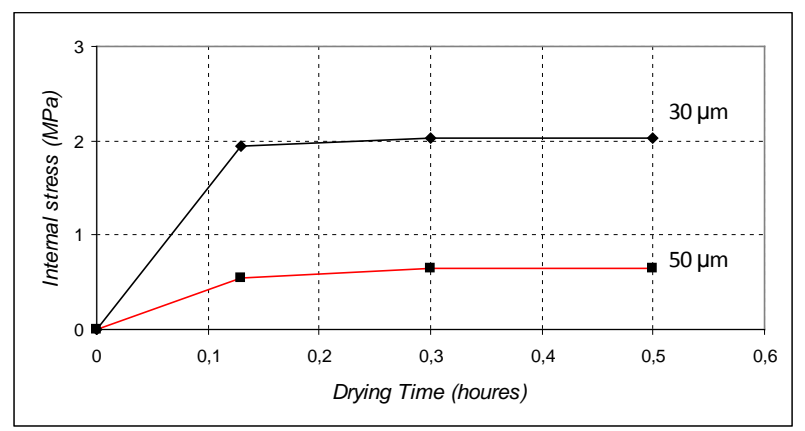

Fig. 3. The internal stress in UV water based lacquer

\section{CONCLUSION}

Based on the theory and experimental analysis presented in this paper, we can conclude that the internal stresses in the films are a negative phenomenon. These results clearly show that thinner films on surfaces $\mathrm{t}=30[\mu \mathrm{m}]$ have higher internal stress $\sigma=2,02[\mathrm{MPa}]$, or conversely thicker films $\mathrm{t}=50[\mu \mathrm{m}]$ have lower internal stresses $\sigma=0,65[\mathrm{MPa}]$.

The presented diagram of a water based lacquers' internal stress confirms the theory of kinetics of internal stresses.

\section{REFERENCES}

Axelsen, S.T.; et al. (2008). Topcoat flaking - a mechanism study. Party 1; Laboratory testing internal stress, mechanical properties, adhesion and ageing, Corrosion, March16-20, New Orleans, USA, Number of pages 14

Grigore, E.; Ruset, C.; Short,; Hoeft, D.; Dong, H.; Li, X.Y. and Bellt, T. (2005) In situ investigation of the internal stress within the nc-Ti2N/nc-TiN nanocomposite coatings produced by a combined magnetron sputtering and ion implantation method, Surface and Coatings Technology, Vol. 200, Iss. 1-4, Oct 2005, pp. 744-747, ISSN O257-8972

Vela, J.B.; Adhihetty, I.S.; Junker, K.; and Volinsky, A.A. (2003) Mechanical Propertis and Fracture Toughness of Organe - silicate Glass (OSG) Low-k Dielectric Thim Films for Microelectronic Application, Int. Journal of Fracture, Vol 119, No.4, pp 487- 499

Volinsky, A.A.; Moody, N.R.; Gerberich, W.W. (2002) Interfacial Toughness Measuremens for Thin Films on Substrates, Act Mater., Vol. 50/30, pp. 441-466

Vukas, N.; Horman, I. and Dover, M. (2010) Analysis of Internal Stress in Polyurethane Coatings, Proceedings of the 2nd 